\title{
Study on Loading Capacity of Miniature Boats Fabricated from Hydrophobic Plant Leaves
}

\author{
Wang Qingcheng ${ }^{1, a}$, Yang Xiaodong ${ }^{2, b}$ and Yang Zhuojuan ${ }^{1, c}$ \\ ${ }^{1}$ School of Mechanical Engineering, Jilin Teachers' Institute of Engineering and \\ Technology, Changchun 130052, China \\ ${ }^{2}$ School of Mechanical and Electric Engineering, Changchun Institute of \\ Technology, Changchun 130021, China \\ awqc9341@163.com, ${ }^{b} y 86908051 @ 126 . c o m,{ }^{c} 450818386 @ q q . c o m$
}

\begin{abstract}
The contact angle of lotus, canna, green poplar, grape and pumpkin were $150.6^{\circ}, 135.5^{\circ}$, $110.4^{\circ}, 101.3^{\circ}$ and $94.8^{\circ}$ respectively, five kinds of plant leaves were adhered to rectangular box by double-sided adhesive tape, which were called miniature boats. Miniature boats have super large loading capacity on water surface through the experimental measurements, loading capacity and water dimple depth increases with contact angle. Through mechanical analysis, the paper established mathematical model of loading capacity, comparing the measured values and measured values of loading capacity, the error ratio of loading capacity is about 4.0-6.1\%. The loading capacity is made up of buoyancy and surface tension, percentage of buoyancy and surface tension in the loading capacity is affected by the contact angle and geometry size of miniature boats.
\end{abstract}

Keywords: Loading capacity, Miniature boats, hydrophobic, plant leaves

\section{Introduction}

The superior loading capacity of water strider's legs on water surface has drawn the public attention and become one of the hot topics researched by scientists and engineering technicians in the world [1-3]. Jiang et al., [4] deemed that this is realized by superhydrophobicity resulting from special micro/nano structure of water strider's leg. Zhang et al. [5] modified surface of gold thread to make it hydrophobic, and found that loading capacity of gold thread on water surface increased greatly, the gold thread with diameter of $1 \mathrm{~mm}$ could float on water surface. Feng et al., [6] researched loading capacity of thin rod with hydrophobic surface, and thought that the loading capacity was related to such factors as contact angle and cross-section radius. Pan et al., [7] researched the loading capacity of miniature boat made from super hydrophobic copper mesh, and thought that air film absorbed to hydrophobic surface could increase loading capacity.

In this paper, miniature boats were fabricated from hydrophobic plant leaves. The maximum loading capacity of miniature boats on water surface was measured, and the mathematical model of loading capacity was established, the relationship between loading capacity and its related factors was analyzed.

\section{The Preparation of Miniature Boats}

Miniature boats were made of the iron sheet, which like a Rectangular box, those length, width and height were shown in Table 1. 
Table 1. The Geometric Data of Miniature Boat

\begin{tabular}{lcccc}
\hline designation & Miniature boat 1 & Miniature boat 2 & Miniature boat 3 & Miniature boat 4 \\
\hline Length $(\mathrm{mm})$ & 40.8 & 40.7 & 40.8 & 40.7 \\
Width $(\mathrm{mm})$ & 10.7 & 20.8 & 30.7 & 40.6 \\
Height $(\mathrm{mm})$ & 5.1 & 5.2 & 5.2 & 5.1 \\
\hline
\end{tabular}

The principles of selecting plant leaves were that there should be some difference among contact angles, and the leaves area should be large. The leaves of lotus, canna, poplar, grape and pumpkin were selected, their contact angle were measured by contact angle meter (DSA100, accuracy of $0.1^{\circ}$, made by KRUSS), which were $150.6^{\circ}, 135.5^{\circ}, 110.4^{\circ}, 101.3^{\circ}$ and $94.8^{\circ}$ respectively.

\section{The Maximum Loading Capacity Measurement and Analysis}

These selected plant leaves were closely adhered to rectangular box by double-sided adhesive tape, namely miniature boats. At first, miniature boats mass were measured by analytical balance (CH-252, accuracy of $0.01 \mathrm{mg}$, made by A\&D Co., Ltd.). Miniature boats were placed on water surface, the iron wire $(40 \mathrm{~mm}$ in length and $0.8 \mathrm{~mm}$ in diameter) were gradually loaded into miniature boats by tweezers. In this process, it could be seen that miniature boats could still float even if its upper edge was lower than water surface, a big water dimple pressed by the miniature boats on water surface as shown in Figure 1. Iron wire was continuously loaded into miniature boats until it broke water surface and submerged in water. The maximum loading capacity of miniature boats was the sum of iron wire weight and itself, as shown in Table 2.

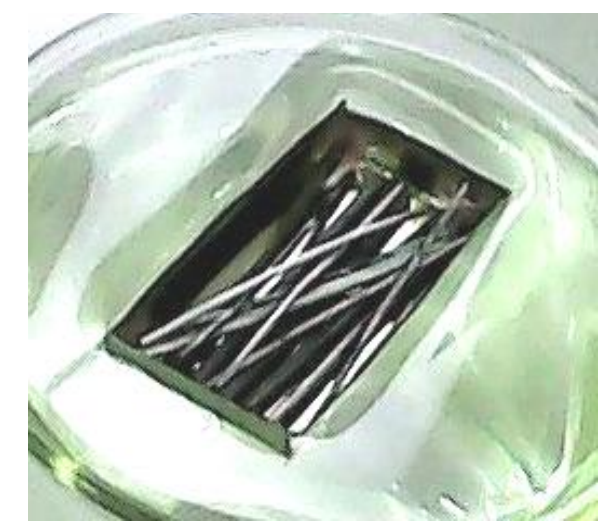

Figure 1. Water Dimple Pressed by Miniature Boats

Analyzing the data in Table 2, the maximum loading capacity of miniature boats increase with the contact angle, as shown in Figure 2, abscissa represents the contact angle of plant leaves, ordinate represents the maximum loading capacity of miniature boats, M1, M2, M3, and M4 represent the miniature boat 1,2,3 and 4, respectively.

Table 2. The Maximum Loading Capacity of Miniature Boat

\begin{tabular}{lcccc}
\hline designation & Miniature boat 1 & Miniature boat 2 & Miniature boat 3 & Miniature boat 4 \\
\hline Lotus & 43173.2 & 76756.5 & 110236.4 & 140057.5 \\
Canna & 38053.4 & 68779.8 & 100010.3 & 126620.1 \\
\hline
\end{tabular}




\begin{tabular}{lllll}
\hline Poplar leaf & 30301.7 & 55718.2 & 80658.0 & 104634.7 \\
Grape leaf & 27802.1 & 52097.3 & 74292.9 & 97068.2 \\
Pumpkin & 24338.3 & 46681.7 & 67715.5 & 88175.6 \\
\hline
\end{tabular}

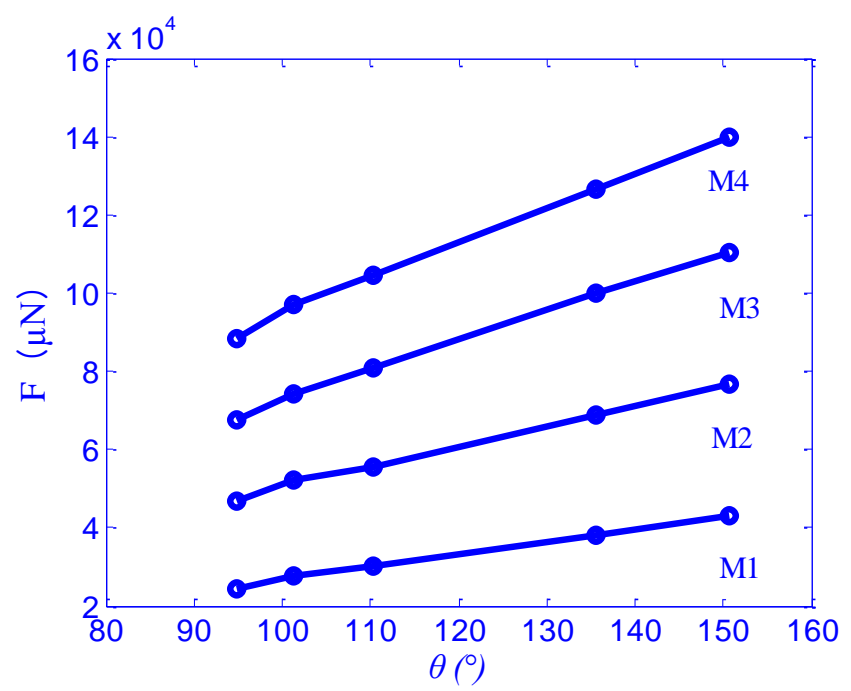

Figure 2. The Influence of Contact Angle on the Loading Capacity

\section{Mathematical Analysis of Loading Capacity}

Seen from Figure 1, the actual water displacement of the miniature boats is greater than its volume because the dimple pressed by miniature boats can increase the water displacement, that is, loading capacity of miniature boats can be increased. The mechanical analysis of cross-section of miniature boats are as shown in Figure 3.

Miniature boats were subject to three forces on water surface, which were called the pressure $F_{Y}$, surface tension $\gamma$ and buoyancy force $F_{b}$. The pressure is vertically downward, which mainly includes miniature boats weight and iron wire weight. The buoyancy force is vertically upward, which can be obtained by integral calculus of static pressure at the area of the miniature boats contacting water [8-10], and is equal to the sum of miniature boats volume and water displacement of rectangle ACDE in Figure 3. The expression of buoyancy force is

$$
F_{b}=\rho a b(c+h) g
$$

In Equation (1), $\rho, \mathrm{g}$ and $\mathrm{h}$ mean water density, gravitational acceleration and dimple depth respectively; a, b and c mean length, width and height of miniature boats respectively.

The surface tension is in the tangential direction of Point $\mathbf{D}$ on liquid-gas interface, the surface tension is divided into horizontal component and vertical component. The expression of vertical component of surface tension is

$$
F_{s}=2 \gamma(a+b) \sin \alpha
$$

In Equation (2), $\gamma$ means surface tension constant, $\alpha$ means horizontal angle tangent of point $\mathbf{D}$ on liquid-gas interface. The vertical component of surface tension was obtained by integral calculation of curved surface pressure at the area of miniature boats contacting water 
surface [8-10], which is equal to the sum of displacement of $\mathbf{A B C}$ area and displacement of DEF area in Figure 3.

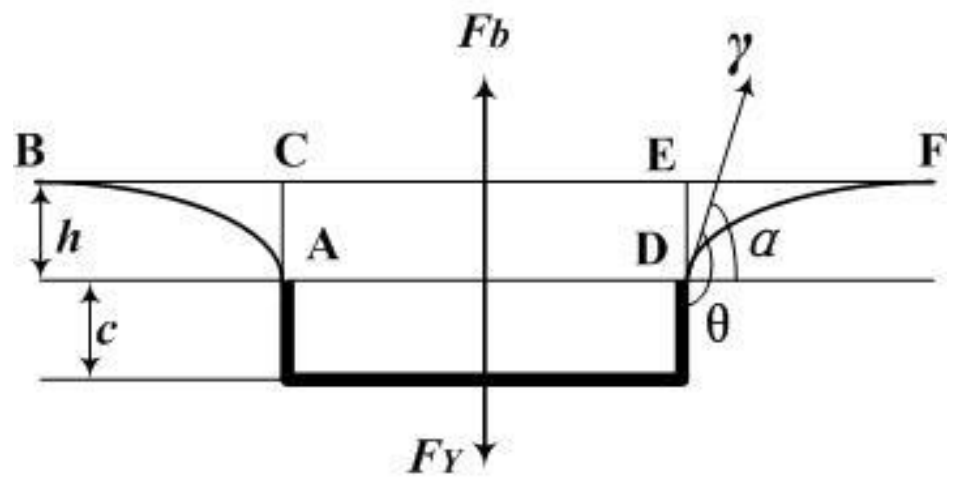

Figure 3. Mechanical Analysis of Cross-section of Miniature Boats

When miniature boats stay on water surface calmly, the pressure, buoyancy force and surface tension are balanced in both vertical and horizontal directions. In horizontal direction, miniature boats are only subject to horizontal component of surface tension; since the dimple is symmetrical, the horizontal components of surface tension cancel out each other. In vertical direction, miniature boats are subject to the pressure, buoyancy force and vertical component of surface tension; the upward force and the downward force are a pair of balanced force. The loading capacity $(\mathrm{F})$ of miniature boats on water surface is equal to the sum of buoyancy force and vertical component of surface tension, and its expression is

$$
F=F_{s}+F_{b}=2 \gamma(a+b) \sin \alpha+\rho a b(c+h) g
$$

According to Figure 3, the expression of $\alpha$ is obtained

$$
\alpha=\theta-\frac{\pi}{2}
$$

In Equation (4), $\theta$ is the contact angle of hydrophobic plant leaves, $90^{\circ}<\theta<180^{\circ}$. By combining the expression (4) with the expression (3), the expression (5) can be obtained

$$
F=\rho a b(c+h) g-2 \gamma(a+b) \cos \theta
$$

Seen from the expression (5), loading capacity $(F)$ is related to such factors as a, b, c, h, $\theta$, $\gamma, \rho, g$. Among them, $\rho$ and $g$ are environmental parameters; $a, b, c$ and $\theta$ are parameters of miniature boats; $h$ is dimple depth.

According to the literatures [11-12], the relational expression of contact angle and the depth of the water dimple is

$$
h=\sqrt{\frac{2 \gamma}{\rho g}(1-\cos \alpha)}=\sqrt{\frac{2 \gamma}{\rho g}(1-\sin \theta)}
$$

See from the equation (6), the contact angle is larger, water dimple is deeper.

\section{Contrast Analysis of Calculated Value and Measured Value}

The contact angle of lotus, canna, poplar, grape and pumpkin were $150.6^{\circ}, 135.5^{\circ}, 110.4^{\circ}$, $101.3^{\circ}$ and $94.8^{\circ}$ respectively, which are taken into the equation (6), the depth of the water 
dimple will be obtained. Combined the data in table 1, which are taken into the equation (1) (2) (5), Buoyancy, surface tension and loading capacity will be obtained, as shown in Table 3.

Table 3. The Maximum Loading Capacity Calculated Value of Miniature Boat

\begin{tabular}{ccccc}
\hline $\begin{array}{c}\text { Serial } \\
\text { number }\end{array}$ & $\begin{array}{c}\text { Water dimple } \\
\text { depth }(\mathbf{m m})\end{array}$ & $\begin{array}{c}\text { Buoyancy } \\
(\boldsymbol{\mu} \mathbf{N})\end{array}$ & $\begin{array}{c}\text { Surface tension } \\
(\boldsymbol{\mu N})\end{array}$ & $\begin{array}{c}\text { loading capacity } \\
(\boldsymbol{\mu})\end{array}$ \\
\hline A1 & 2.75 & 38432.2 & 6728.0 & 45160.2 \\
B 1 & 2.11 & 34661.2 & 5479.5 & 40140.7 \\
C 1 & 0.97 & 29121.7 & 2672.8 & 31829.5 \\
D 1 & 0.54 & 27456.2 & 1504.3 & 28960.5 \\
E1 & 0.23 & 24942.2 & 650.1 & 25592.3 \\
A 2 & 2.75 & 73214.7 & 8009.1 & 81223.8 \\
B 2 & 2.11 & 66180.6 & 6516.0 & 72696.6 \\
C 2 & 0.97 & 55841.1 & 3182.4 & 59023.5 \\
D 2 & 0.54 & 52365.7 & 1789.5 & 54155.2 \\
2 & 0.23 & 48224.4 & 759.5 & 48983.9 \\
A 3 & 2.75 & 106529.6 & 9264.9 & 115794.5 \\
B 3 & 2.11 & 97490.0 & 7562.8 & 105052.8 \\
C 3 & 0.97 & 81934.2 & 3690.0 & 85624.2 \\
D 3 & 0.54 & 76460.1 & 2073.6 & 78533.7 \\
E 3 & 0.23 & 71003.5 & 881.3 & 71884.8 \\
A 4 & 2.75 & 138637.9 & 10518.1 & 149156.0 \\
B 4 & 2.11 & 126265.1 & 8580.6 & 134845.7 \\
C 4 & 0.97 & 106531.0 & 4193.5 & 110724.5 \\
D4 & 0.54 & 99819.2 & 2358.3 & 102177.5 \\
E 4 & 0.23 & 92207.2 & 1001.7 & 93208.9 \\
\hline
\end{tabular}

In Table 3, A, B, C, D, E represent lotus, canna, poplar, grape and pumpkin respectively, 1, 2,3 , and 4 represent the miniature boat $1,2,3$ and 4 respectively.

The error comparison of the measured values of loading capacity in Table 2 and the calculated value in table 3 is conducted, as shown in Figure 4. The error range of measured values and calculated values is $1158.4-9098.5 \mu \mathrm{N}$, the ratio of error and calculation value of loading capacity is $4.0-6.1 \%$.

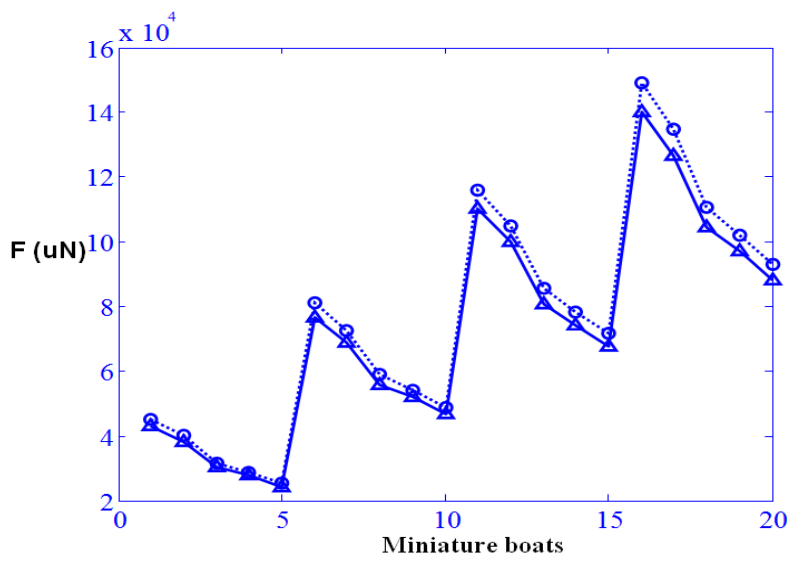

Figure 4. Loading Capacity Contrast Analysis of Calculated Value and Measured Value for Miniature Boat 
In Figure 4, 1-5 is the value of loading capacity of miniature boat 1, 6-10 is the value of loading capacity of miniature boat 2,11-15 is the value of loading capacity of miniature boat $3,16-20$ is the value of loading capacity of miniature boat 4 , the sequence of loading capacity value is the lotus, canna, poplar, grape and pumpkin respectively.

\section{Contribution of Buoyancy and Surface Tension for Loading Capacity}

The contribution of buoyancy and surface tension for loading capacity is shown in Figure 5, there are 5 lines in Figure 5, A, B, C, D, E represent the lotus, canna, poplar, grape and pumpkin respectively, 1,2,3, and 4 represent the miniature boat $1,2,3$ and 4 respectively. Blue part represents buoyancy, white part represents surface tension.

As can be seen from changing of every row in Figure 5, for the same contact angle of the miniature boat, percentage of the buoyancy in the loading capacity increases with the size of miniature boat increasing, percentage of the surface tension in the loading capacity decreases with the size of miniature boat decreasing. As can be seen from changing of every column in Figure 5, for the same size of the miniature boat, percentage of the buoyancy in the loading capacity decreases with the contact angle increasing, percentage of the surface tension in the loading capacity increases with the contact angle.
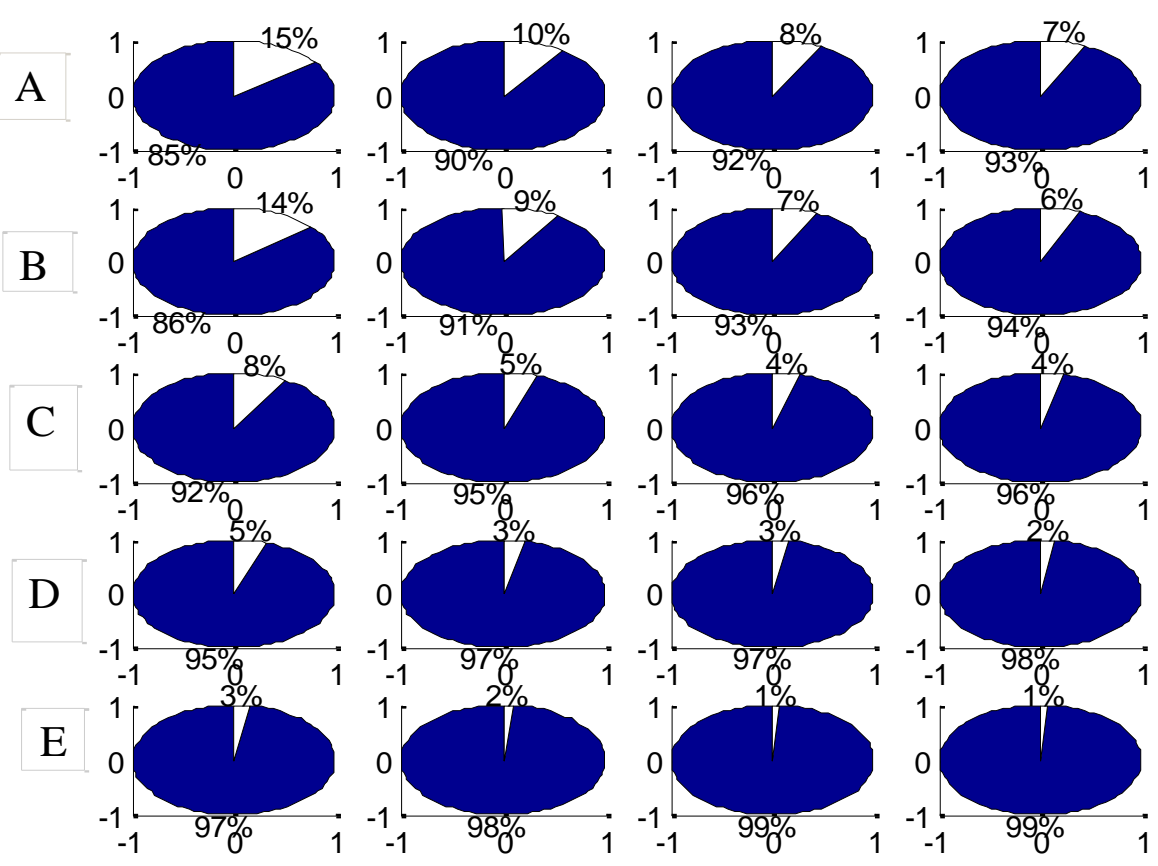

Figure 5. Contribution of Buoyancy and Surface Tension on Loading Capacity

\section{Conclusion}

(1) This paper designed measurement experiment of loading capacity for the miniature boat fabricated from the hydrophobic leaves. Loading capacity can improve greatly through water dimple pressed by the hydrophobic plant leaves, loading capacity and water dimple depth increase with the contact angle increasing. 
(2) Through mechanical analysis, this paper established the mathematical model of the loading capacity, comparing the measured values and measured values of loading capacity, the error ratio of loading capacity is about $4.0-6.1 \%$.

(3) The loading capacity is made up of buoyancy and surface tension, for the same contact angle of the miniature boat, percentage of buoyancy in the loading capacity increases with the size of miniature boat, surface tension is in contrast to the buoyancy; for the same size of the miniature boat, percentage of the surface tension in the loading capacity increases with the contact angle, buoyancy is in contrast to the surface tension 。

\section{Acknowledgement}

This work was supported by National Natural Science Foundation of China (51275055), Jilin Province Science and Technology Development Project (20140101058JC) and Jilin Provincial Department of Education funded project (2013370).

\section{References}

[1] M A Caponigro and C H Erilsen, "Surface film locomotion by the water strider", gerris remigis, The American Midland Naturalist, vol. 95, no. 2, (1976), pp. 268-278.

[2] M. Dickinson, "Animal locomotion: how to walk on water", Nature, (2003), vol. 424, no. 6949, pp. 621-622.

[3] D. L. Hu, B. Chan and J. W. M. Bush, "The hydrodynamics of water strider locomotion, Nature, vol. 424, no. 6949, (2003), pp. 663-666.

[4] X F Gao and L. Jiang, "Water-repellent legs of water striders", Nature, vol. 432, no. 26, (2004).

[5] S. Feng, N. Jia and L. Jianlin, et al. "Towards understanding why a superhydrophobic coating is needed by water striders", Adv. Mater., vol. 19, (2007), pp. 2257-226.

[6] J L Liu, X Q Feng and G L Wang, "Buoyant force and sinking conditions of a hydrophobic thin rod floating on water", Physical Review E, (2007), vol. 76, pp. 066-103.

[7] Q. Pan and M. Wang, "Miniature boats with striking loading capacity fabricated from superhydrophobic copper meshers", ACS Applied Materials \& Interfaces, vol. 1, no. 2, (2009), pp. 420-423.

[8] D. Vella, D.-G. Lee and H.-Y. Kim, "The Load Supported by Small Floating Objects", Langmuir, (2006), vol. 22, pp. 5979-5981.

[9] Q. Pan, J. Liu and Q. Zhu, "A water strider-like model with large and stable loading capacity fabricated from super hydrophobic copper foils”, ACS Applied Materials \& Interfaces, vol. 2, no. 7, (2010), pp. 2026-2030.

[10] P. J. Wei, Y. X. Shen, and J. F. Lin, "Characteristics of Water Strider Legs in Hydrodynamic Situations", Langmuir, vol. 25, no. 12, (2009), pp. 7006-7009.

[11] Q. Wang and X. Yang, "Modeling and analysis of the supporting force of water strider's legs", Applied Mechanics and Mechanical, (2011), pp. 138-139, pp. 356-361.

[12] S. Wang and L. Wu, "Statics analysis on the leg of water strider robot", Journal of Beijing University of Aeronautis and Astronautis, vol. 36, no. 10, (2010), pp. 1176-1179. 
International Journal of Hybrid Information Technology Vol. 7, No. 6 (2014) 